\title{
Evaluation of Hepatitis B, Hepatitis C and HIV Seropositivity in Chronic Urticaria Patients
}

\author{
Nihal Altunışık ${ }^{1}$, Sibel Altunışık Toplu², Serpil Şener ${ }^{1}$ \\ 1'̇nonu University Faculty of Medicine, Department of Dermatology \\ ${ }^{2}$ İnonu University Faculty of Medicine, Department of İnfectious Diseases and Clinical Microbiology \\ Received: 11 February 2019, Accepted 26 April 2019, Published online: 31 December 2019 \\ (C) Ordu University Institute of Health Sciences, Turkey, 2019
}

\begin{abstract}
Objective: Many factors are responsible for the etiology of chronic urticaria. In this study, we aimed to determine the relationship between chronic urticaria and hepatitis $\mathrm{B}$, hepatitis $\mathrm{C}$ and human immunodeficiency virus (HIV).

Methods: The study included patients with chronic urticaria who were admitted to our dermatology outpatient clinic between July 2018 and January 2019. Hepatitis B surface antibody (anti-HBs), hepatitis B surface antigen ( $\mathrm{HBsAg}$ ), hepatitis $\mathrm{C}$ antibody (anti-HCV) and human immunodeficiency virus antibody (anti-HIV) were recorded retrospectively.

Results: A total of 57 patients were included in the study. Of the 57 patients, 38 (66.7\%) were female and $19(33.3 \%)$ were male. The mean age of the patients was $41.2 \pm 13.5$ (minimum / maximum: 19-74). In thirtytwo patients $(56.1 \%)$, anti-HBs positivity was detected and in $25(43.9 \%)$ negative. None of the patients had HBsAg positivity and HCV antibody positivity. Even though HIV antibody positivity was detected in one patient, the result of the validation test was reported as negative.

Conslusion: In our study, no relation was found between chronic urticaria and hepatitis B, hepatitis C and HIV. However, in patients with chronic urticaria, we think that there are more cases and multicenter studies to get an idea of whether screening for hepatitis and HIV should be done routinely.
\end{abstract}

Key words: Chronic urticaria, anti-HBs, anti-HCV, anti-HIV

Suggested Citation: Altunisik N, Altunisik Toplu S, Sener S. Evaluation of Hepatitis B, Hepatitis C and HIV Seropositivity in Chronic Urticaria Patients. Middle Black Sea Journal of Health Science, 2019; 5(3): 175-179.

Address for correspondence/reprints:

Sibel Altunışık Toplu

Telephone number: +90 (536) 2385799

E-mail: sibel.toplu@inonu.edu.tr

DOI: $10.19127 / \mathrm{mbsjohs.525212}$

\section{Introduction}

Urticaria is defined as an itchy, erythematous and marked lesion that develops in the upper layers of the dermis due to vasodilatation and edema in the veins. According to the duration of lesions can be classified as acute and chronic. Chronic urticaria is defined as urticaria lesions lasting 6 weeks or longer. In patients with acute urticaria, it is easier to determine the causative agent and often food and drugs are responsible, but $40 \%$ of chronic urticaria cases cannot be detected. However, factors that play a role in the etiology of chronic urticaria include drugs, autoimmune diseases, infections, foods and psychogenic factors (Kaya and Akyol, 1999; 
Ozdemir and Yazıcıoglu, 2012; Inci and Gunaydın, 2015; Sarac et al., 2018).

Chronic urticaria is seen in $0.5 \%$ of the population. The disease is seen in the adult age group, especially in middle-aged female patients. There is no clear data on the frequency of chronic urticaria in childhood (Ozdemir and Yazıcioglu, 2012).

In the pathogenesis of urticaria, an increase in the regional vasodilatation and vascular permeability due to the effect of various vasoactive mediators, mainly histamine, plays an important role. The release of histamine and other vasoactive mediators is mediated by the effect of $\operatorname{IgE}$ antibody on the basophils or tissue mast cell surface with antigen, by the effect of C3a, C4a, C5a mediated by the complement system, or by histamine secreting agents released from mononuclear cells. In addition to histamine and other mediators, increased vascular permeability activates the plasma quinine system. Bradykinin as a result of activation of plasma kinin system also contributes to increased vasodilatation and permeability (Ozdemir and Yazıcıoglu, 2012). The hypothesis that chronic urticaria may be autoimmune for the first time has been proposed in 1960. In cases where the autologous serum skin test is positive, it is argued whether the autorespactivity is triggered by the autoantibodies or by the serum or plasma factor. The fact that basophils obtained from patients with chronic urticaria exhibit different responses in various tests compared to normal individuals suggested that a cellular defect in basophils may play a role in the pathogenesis. There is some information that chronic urticaria can be triggered by $\mathrm{H}$. pylori, hepatitis and can be eliminated with the treatment of infectious agent. There are also case series associated with food and food preservatives. However, the evidence is not yet sufficient (Gungor and Akyol, 2014).

While many factors are considered responsible for the etiopathogenesis of chronic urticaria, recent studies have shown that infections have an important role in the etiology of urticaria. Upper respiratory tract infection, urinary tract infection, tooth infection, genital infection, chronic hepatitis B and $\mathrm{C}$ infections can be considered as a focus of infection (Kose et al., 2011).

Although the relationship between chronic urticaria and hepatitis has been known for a long time, the pathogenesis has not been fully understood. The accused mechanisms are the formation of degranulation of mast cells in the circulating antigens and complement activation via immune complexes (Inci and Gunaydin, 2015). Although there are cases in the literature where acute urticaria has been reported as the first sign of HIV infection, the frequency of chronic spontaneous urticaria in HIV-infected patients is not fully known (Iemoli et al., 2017).

In this study, we evaluated the results of anti$\mathrm{HBs}, \mathrm{HBsAg}$, anti-HCV and anti-HIV in patients with chronic urticaria. It is aimed to compare with literature data.

\section{Methods}

The study included patients with chronic urticaria who were admitted to the dermatology clinic between July 2018 and January 2019. Ethics committee approval and patient approval could not be obtained because it is a retrospective study that should be performed in accordance with the principles of the Helsinki Declaration. Diagnosis of urticaria was made by clinical findings. Patients with erythematous, edematous papules and plaques on the trunk were diagnosed as urticaria. Patients with a duration of disease longer than 6 weeks were accepted as chronic urticaria. The patients were evaluated retrospectively and gender, age, HBsAg, anti-HBs, anti-HCV and anti-HIV results were recorded. Anti-HBs was considered positive for those above $10 \mathrm{u} / \mathrm{ML}$.

SPSS (Statistical Program for Social Sciences) 22 package program was used for statistical evaluation of the study. Normally distributed variables were shown as mean \pm standard deviation.

\section{Results}

A total of 57 patients were included in the study. Of the 57 patients, $38(66.7 \%)$ were female and 19 $(33.3 \%)$ were male. The mean age of the patients was $41.2 \pm 13.5$ (minimum / maximum: 19-74). Thirty-two patients $(56.1 \%)$ had anti-HBs positive and $25(43.9 \%)$ patients were negative. In our patients, $\mathrm{HBcAg}$ (hepatitis core antigen) was not examinated. Therefore, in our study, it was not possible to differentiate patients with anti-HBs positivity from those with previous infection or vaccination-related positivity. Positivity for $\mathrm{HBsAg}$, $\mathrm{HCV}$ antibody positive and none of the patients was not found. The results of the validation test were reported as negative even if HIV antibody positivity was detected in a patient (Table 1). 
Table1. Anti-HBs, HBsAg, anti-HCV and anti-HIV results in patients with chronic urticaria

\begin{tabular}{crcc}
\hline & Positive & Negative & Total \\
\cline { 2 - 4 } Anti-HBs & & & \\
Female & 16 & 22 & 38 \\
Male & 9 & 10 & 19 \\
HBsAg & - & 57 & 57 \\
Anti-HCV & - & 57 & 57 \\
Anti-HIV & 1 & 56 & 57 \\
\hline
\end{tabular}

\section{Discussion}

Urticaria is a disease characterized by erythematous, itchy papules and plaques in varying diameters. Chronic urticaria is defined if attacks last more than six weeks.

Urticaria is common in the community. $15-20 \%$ of people experience an attack of urticaria at least once in their lives. Acute urticaria is more common in children and young adults and chronic urticaria in middle-aged women. In our study, the majority of patients were female and middle-aged.

In chronic urticaria, many factors are responsible for release of certain mediators, especially histamine, from basophils and mast cells in immunological or non-immunological ways. But it is often difficult to determine the causative agent. Determining the etiology is important because it will affect the success of the treatment. Since all types of viral, bacterial, fungal and parasitic infections can cause urticaria, the focus of infection should be investigated in patients. Bacterial infections may be caused by respiratory tract, genitourinary system, dental, gastrointestinal tract. Hepatitis B and hepatitis $\mathrm{C}$ infections from viral infections are responsible for the etiology of chronic urticaria (Arican and Kutluk, 2005).

Viral hepatitis is a serious public health problem in our country and is frequently transmitted via blood. The incidence of hepatitis B virus in our country varies between $20.6 \%$ and $56.3 \%$. The seroprevalence of the hepatitis $\mathrm{C}$ virus in our country is $0.3 \%-1.8 \%$. Hepatitis $\mathrm{B}$ and hepatitis $\mathrm{C}$ virus can cause cirrhosis, hepatocellular carcinoma and chronic hepatitis. In recent years, it has been suggested that viral hepatitis may be associated with many other autoimmune diseases such as mixed cryoglobulinemia, polyarteritis nodosa and Sjögren syndrome, other than liver findings. In addition, hepatitis $\mathrm{C}$ virus can be associated with many dermatological diseases such as pruritus, porphyria kutanea tarda, vasculitis, salivary gland lesions, lichen planus, necrolitic acral erythema (Balik, 1994a; Çakaloğlu, 1994b; Gül and Çevik, 1998;
Bilen et al., 1999; Oztas et al., 2007; Inci and Gunaydın, 2015).

The relationship between chronic urticaria and viral hepatitis has been known for a long time. Some mechanisms such as insufficient clearance of immune complexes as a result of viral hepatitisrelated macrophage function disorder, hepatitis virus stimulating the release of mediators from mast cells, immune complexes in circulation, release of antigens not related to HBV to circulating from infected hepatocytes are accused of etiopathogenesis. In addition, autoimmune mechanisms that play a role in the etiopathogenesis of chronic urticaria are thought to be triggered by agents with immunological effects such as HCV infection (Gul and Cevik, 1998; Dervis et al., 2001). In other studies, the pathophysiology of the disease is thought to be the formation of immune complexes in the blood and the accumulation of these immunocomplexes in the vessel wall. It is emphasized here that the process is associated with certain conditions in which antigen antibody complexes are well defined. Hepatitis B and C are the leading ones (Jones et al., 1983; Berg et al., 1988; Jerry et al., 1999). However, the opinions at the hypothesis level need to be supported.

Dermatological findings in the skin and mucous membranes of HIV-positive patients are important both in the diagnosis and progression of the disease. Recent studies have shown that herpes simplex virus infection, candidiasis, and seborrheic dermatitis are more common in HIV positive patients than in normal populations (Dilek and Saral, 2014). In addition, increased serum IgE levels can be detected in HIV infection. The increase in serum IgE levels is related to the imbalance between the $\mathrm{T}$ helper 1 and $\mathrm{T}$ helper 2 cytokine profile and the low peripheral TCD4 + T cell count caused by disease progression (Iemoli et al, 2017). Although there are many studies about the relationship between chronic urticaria and viral hepatitis in the literature, we did not find any comprehensive study examining the relationship between chronic urticaria and HIV positivity. In our study, a patient with chronic urticaria who was followed because of HIV positivity could not be detected. This situation may be related to the evaluation of patients with chronic urticaria during dermatology outpatient follow-up. Patients with HIV may also be evaluated in terms of chronic urticaria. Remarkably, chronic urticaria in the literature has been reported as the first sign of HIV infection (Friedman et al., 1995). 
Iemoli et al, 56-year-old, HIV-positive, homosexual, men with a chronic urticaria treated with omalizumab reported (Iemoli et al, 2017).

In the study performed by İnci and Günaydın, 56 chronic urticaria cases were examined, 21 patients had anti-HBs positivity and 2 patients had HBsAg positivity. However, none of the patients had antiHCV positivity (Inci and Gunaydın, 2015). Anti$\mathrm{HCV}$ antibody positivity was found in 4 of 55 chronic urticaria patients in the study of Arinkal et al. (Arinkal et al., 2001). In another study, 36 patients with chronic urticaria were examined and none of them had anti-HCV antibody positivity. Therefore, the authors concluded that there is no need for anti-HCV investigation in patients with chronic urticaria who have no risk factor for HCV infection and normal liver function tests (Bilen et al., 1999). In a study by Erel et al., the seroprevalence of $\mathrm{HBV}$ and $\mathrm{HCV}$ in patients with chronic urticaria was similar to the normal population (Erel et al., 1999).

In some of the studies in the literature, patients with chronic urticaria reported higher rates of $\mathrm{HCV}$ antibody positivity than the normal population. Kazarava et al., 1996, in their study, 58 of 79 patients with chronic urticaria in $19(24 \%)$ anti-HCV positivity has been found (Kanazawa et al., 1996).

In our study, none of the patients had HBsAg positivity and $\mathrm{HCV}$ antibody positivity. Even though HIV antibody positivity was detected in one patient, the result of the validation test was reported as negative. To determine the etiopathogenesis, whether HBsAg, anti-HCV and anti-HIV tests are to be performed in all patients should be evaluated in terms of cost effectiveness.

As a result, although studies in the literature that support the relationship between chronic urticaria and chronic hepatitis in our study none of the patients are hepatitis $\mathrm{B}$, hepatitis $\mathrm{C}$ and HIV seropositivity could not be detected. However, in patients with chronic urticaria, we think that a wider range of cases and multi-center studies should be undertaken in order to have an idea of whether or not to have hepatitis and HIV screening routinely.
Ethics Committee Approval: Ethical committee approval was not obtained because the data were retrospectively reviewed in our study

Peer-review: Externally peer-reviewed.

Author Contributions: Concept- A. N, T. SA, SS.S Design- A. N, T. SA, Ş.S., Supervision- A. N, T. SA, Ş.S, Literature Review- A. N, T. SA, Ş.S, WritingA. N, T. SA, Ş.S, Critical Review- A. N, T. SA, Ş.S. Conflict of Interest: No conflict of interest was declared by the author.

Financial Disclosure: The author declared that this study hasn't received no financial support.

\section{References}

Arican O, Kutluk R. Etyopathogenesis in Urticaria. Kartal Education and Research Hospital Medical Journal 2005; 16(1): 46-52.

Arinkal IZ, Buyuk AY, Sudogan S, Akkiz S, Kavala M. Incidence of Anti HCV Antibody in Chronic Idiopathic Urticaria. Göztepe Medical Journal 2001; 16(1): 14-6.

Balik D. Hepatit B Epidemiyolojisi. Viral Hepatit 94. K1lıçturgay K editor. İstanbul: Tayf Ofset; 1994. p. 91-102.

Berg RE, Kantor GR, Bergfeld WF. Urticarial vasculitis. Int J Dermatol 1988; 27:468.

Bilen N, Apaydin R, Mutlu B, Bayramgurler D, Yildirim G. Should Hepatitis C Virus Infection $\mathrm{Be}$ Investigated in the Cases of Choronic Urticaria? T Clin Dermatology 1999; 9(3): 134136.

Cakaloglu Y. Hepatitis C virus infection. Epidemiology, pathogenesis, clinical, treatment. Viral Hepatit 94. Kilıcturgay K, editor. Istanbul: Tayf Ofset; 1994. p. 191-235.

Dervis E, Sonmezoglu M, Varnalı E, Ersoy L, Karaoglu A. Prevalence of Hepatitis B Virus Infection in Patients with Urticaria. Viral Hepat $\mathrm{J}$ $2001 ; 7(1): 1-4$.

Dilek N, Saral Y. Skin Manifestations of HIV Infection. Turkiye Klinikleri J Dermatol-Special Topics 2014; 7(1): 15-26.

Erel A, Oruk S, Senol E, Gurer MA. Seroprevelance of Hepatitis B Virus and Hepatitis C Virus in Chronic Urticaria. T Clin Dermatology 1999 ;10(1): 13-15.

Friedman D, Picard-Dahan C, Grossin M, Belaich S. Chronic urticaria revealing an HIV infection. Eur J Dermatol 1995; 5:40 
Gul U, Cevik MA. Hepatitis A, B, C Virus Seroprevalence in Chronic Urticaria. Journal of Internal Medicine 1998; 5(6): 385-7.

Gungor HK, Akyol A. Pathogenesis of Chronic Urticaria. Turk J Dermatol 2014;4:223-6.

Iemoli E, Niero F, Borgonovo L, Cossu MV, Piconi S. Successful Omalizumab treatment in HIV positive patient with chronic spontaneous urticaria: a case report. Eur Ann Allergy Clin Immunol. $2017 ; 49$ (2): 88-91.

Inci A, Gunaydin A. Evaluation of Hepatitis B and Hepatitis C Frequency in Patients with Chronic Urticaria. IKKSST Journal 2015; 7(1): 1316.doi:10.5222/iksst.2015.013.

Jerry D Brewer, MD, MS, FAADMark DP Davis, MD, FAA. Urticarial vasculitis. Black AK. Urticarial vasculitis. Clin Dermatol 1999; 17:565.

Jones RR, Bhogal B, Dash A, Schifferli J. Urticaria and vasculitis: a continuum of histological and immunopathological changes. $\mathrm{Br} \mathrm{J}$ Dermatol 1983; 108:695.

Kanazawa K, Yaoita H, Tsuda F, Okamoto H. Hepatitis $C$ virus infection in patients with urticaria. J Am Acad Dermatol 1996; 35(2): 1958.

Kaya TI, Akyol A. Pathogenesis of urticaria: Recent Advances in the Subject of Chronic Idiopathic Urticaria Pathogenesis. Turkiye Klinikleri J Dermatol 1999; 9(1): 41-50.

Kose S, Senger SS, Cavdar G. Focal Infections Accompanying Urticaria, a Common Skin Disease. Klimik Journal 2011; 24(2): 98100.doi:10.5152/kd.2011.23.

Ozdemir PG, Yazıcıŏlu M. Choronic Urticaria: Etiology and Pathogenesis: Review. Türkiye Klinikleri J Pediatr 2012;21(1):21-6.

Oztas P, Polat M, Yalcin B, Gur G, Tamer E, Alli N. Hepatitis C Virus-Associated Cutaneous Disorders: Differantial Diagnosis. Turkiye Klinikleri J Med Sci 2007, 27(1):136-138.

Sarac G, Mantar I, Sener S, Cenk H, Kapicioglu Y. Assessment of change in neutrophil-lymphocyte ratio, platelet-lymphocyteratio in patients with acute and chronic urticaria. 2018;25(4)719-22. DOI: 10.5455/annalsmedres.2018.07.132. 